\title{
STUDENTS' SELF-EFFICACY IN THEIR SELF-REGULATED LEARNING STRATEGIES: A DEVELOPMENTAL PERSPECTIVE
}

\author{
Frank PAJARES ${ }^{1)}$ and Giovanni VALIANTE') \\ ${ }^{1)}$ Emory University, U. S. A. and ${ }^{2)}$ Rollins College, U. S. A.
}

\begin{abstract}
The purpose of this study was to provide a developmental perspective on students' self-efficacy in their self-regulatory learning strategies using data obtained from cohort groups of students ranging from age 9 to $17(N=1257)$, to determine whether this confidence differs as a function of gender, and to discover whether these differences are a function of gender orientation beliefs rather than of gender. Confidence in self-regulation decreased as students progressed from elementary school to high school, and the decrease was steeper than a similar decrease in selfperceptions of academic competence. Gender differences favored girls, but these differences were rendered nonsignificant when gender orientation beliefs were controlled. Instead, a feminine orientation was particularly adaptive. Findings support the contentions of researchers who have argued that gender differences in academic motivation may be a function of the stereotypical beliefs that students hold about gender.
\end{abstract}

Key words: self-efficacy, self-efficacy for self-regulation, self-regulated learning, gender differences in academic motivation, academic motivation

With the publication of Social Foundations of Thought and Action, Albert Bandura (1986) proposed a sociocognitive theory of human functioning in which individuals are viewed as proactive and self-regulating rather than as reactive and shaped by external forces. According to this sociocognitive perspective, individuals possess a self system that houses the fundamental human capabilities to symbolize, learn from others, plan alternative strategies, and engage in self-reflection. This system also plays a prominent role in providing reference mechanisms and a set of subfunctions for perceiving, regulating, and evaluating one's own behavior.

The self system serves a self-regulatory function by providing individuals with the capability to alter their environments and influence their own actions. Individuals are said to be self-regulating when they employ the metacognitive skills required to become aware of the capabilities, strategies, and resources required to effectively perform a task, as well as when they engage in planning, monitoring, and evaluating the effectiveness of the activities in which they engage (Stipek, 1998; Zimmerman, 2000). Individuals can regulate their own functioning by monitoring and adjusting their environmental conditions, their performance processes, and even their cognitive and affective states. In school, for example, students regulate their environments when they organize their study area or their class notes, they regulate their performance processes when they plan and

Correspondence concerning this article should be addressed to Frank Pajares, Division of Educational Studies, Emory University, 1784 N. Decatur Rd., Suite 240, Atlanta, GA 30322, U.S.A. (E-mail: mpajare@emory.edu). 
organize the work that needs to be done, and they regulate their mental states when they set proximal goals or estimate and budget their time. Effective self-regulation requires students to engage in continual self-observation, self-evaluation, and self-correction.

The quality of the self-regulatory skills that students employ depends in part on several underlying beliefs that students hold about themselves. Key among these beliefs are students' judgments of their capability to accomplish tasks and succeed in activities, or self-efficacy beliefs. Individuals create and develop self-efficacy beliefs that become instrumental to the goals they pursue and to the control they are able to exercise over their environments. Since Bandura's (1977) introduction of the concept of self-efficacy, educational researchers have investigated the role that these self-perceptions play in the academic lives of students at all levels. Two decades of research findings have now confirmed that students' academic self-efficacy beliefs influence their academic attainments and mediate the effect of skills or other self-beliefs on these attainments (Bandura, 1997; Pajares, 1997). Students' self-efficacy beliefs also influence the selfregulated learning strategies they use in school.

Students who believe they are capable of performing academic tasks use more cognitive and metacognitive strategies, and, regardless of previous achievement or ability, they work harder, persist longer, and persevere in the face of adversity. Students with high self-efficacy also engage in more effective self-regulatory strategies, such as monitoring their academic work time effectively (Pintrich \& De Groot, 1990; Schunk \& Ertmer, 2000). And as students' self-efficacy increases, so does the accuracy of the selfevaluations they make about the outcomes of their self-monitoring (Bouffard-Bouchard, Parent, \& Larivèe, 1991). Self-efficacy in mathematics has also been found positively related to the strategy of reviewing notes and negatively related to relying on adults for assistance (Zimmerman \& Martinez-Pons, 1990).

How people behave can often be better predicted by their self-efficacy beliefs than by what they are actually capable of accomplishing, for these self-perceptions help determine what individuals do with the knowledge and skills they have. For example, self-efficacy beliefs influence the choice of majors and career decisions of college students to a greater degree than does their subject knowledge (see Hackett, 1995). In many cases, unwarranted low confidence, rather than lack of capability, is responsible for maladaptive academic behaviors and diminishing school interest and achievement.

Because self-efficacy beliefs are such powerful predictors of motivational and academic practices, Zimmerman and his colleagues have investigated students' confidence that they possess the self-regulated learning strategies required to succeed in school. After all, self-regulatory skills will hardly serve students who lack the confidence to use them. Researchers have found that this "self-efficacy for self-regulated learning" influences students' motivation, the self-regulatory strategies in which they engage, and the academic success they experience (Zimmerman, 1989, 1990, 1994; Zimmerman \& Martinez-Pons, 1990). Zimmerman, Bandura, and Martinez-Pons (1992) demonstrated that students' self-efficacy for self-regulated learning influenced the confidence students had in their academic capabilities and, through that influence, affected the final grades they obtained. Academic self-efficacy influenced achievement directly as well as 
indirectly by raising students' grade goals. In another study, students' language arts selfefficacy predicted the personal standards they used to judge the quality of the writing they considered self-satisfying as well as their goal setting and writing skill (Zimmerman \& Bandura, 1994).

Researchers have found that students' self-efficacy for self-regulated learning is related to motivation and achievement in academic areas such as language arts, mathematics, and science. Students' confidence in their self-regulated learning strategies is related to their academic self-concept, self-efficacy, value of school and of particular school subjects, achievement goals, and academic performances. It is also negatively related with academic and subject-specific anxiety (Pajares, 2001; Pajares \& Valiante, 1999, 2001; Pajares, Britner, \& Valiante, 2000; Pajares Miller, \& Johnson, 1999).

As individuals mature, their repertoire of self-regulatory strategies increases (Zimmerman, in press). Similarly, as children grow and learn, their academic competence increases. Naturally, students acquire academic knowledge and skills as they progress through school. Interestingly, however, students' confidence in their academic competence does not grow commensurate with their broadening knowledge base and academic expertise. Findings often show that students' academic self-efficacy perceptions decline as they advance through school. This decline has been attributed to factors such as increased competition, norm-referenced grading, less teacher attention to individual student progress, and stresses associated with school transitions. Some researchers have traced the start of this decline in academic self-efficacy to the transition from elementary school to junior high or middle school (Wigfield, Eccles, MacIver, Reuman, \& Midgley, 1991). However, although findings are available as regards decreases in students' self-efficacy in specific academic subject areas such as mathematics or language arts, researchers have not yet investigated whether students' confidence in their self-regulatory strategies follows a similar trajectory. Winne and Perry (2000) rightly argued that until measurements regarding self-regulated learning are "collected across the age spectrum, understandings about developmental trajectories will remain elusive" (pp. 563-564).

Gender differences in students' academic self-efficacy and in their self-efficacy to employ self-regulatory strategies are often reported. For example, boys and girls report equal confidence in their mathematics ability during the elementary years, but, by middle school, boys begin to rate themselves more efficacious than do girls (Wigfield, Eccles, \& Pintrich, 1996). Conversely, in areas related to language arts, male and female students exhibit similar confidence despite the fact that the achievement of female students is typically greater (see Pajares, in press).

When gender differences in the use of self-regulated learning strategies or in confidence to use these strategies have been reported, they typically favor female students. Zimmerman and Martinez-Pons (1990) interviewed students in grades 5, 8, and 11 to discover whether gender differences could be detected in their use of 14 self-regulated learning strategies. Girls displayed more goal-setting and planning strategies, and they kept records and self-monitored more frequently than did boys. Girls also surpassed boys in their ability to structure their environment for optimal learning. Pokay and Blumenfeld 
(1990) investigated the use of self-regulated learning strategies by high school students in geometry and found that, as the semester began, girls reported using more metacognitive, general cognitive, and specific geometry strategies than did boys. Girls also reported stronger effort management. At the end of the semester, girls continued to report stronger general cognitive strategy use.

Some researchers have also reported that girls express greater self-efficacy for selfregulation than do boys during elementary school (Pajares et al., 1999) and middle school (Pajares et al., 2000; Pajares \& Valiante, 2001). Girls express greater confidence in their capability to use strategies such as finishing homework assignments on time, studying when there are other things to do, remembering information presented in class and textbooks, and participating in class discussions.

But gender differences in self-efficacy can be confounded by other factors, however. For example, numerous researchers have argued that some gender differences in social, personality, and academic variables may actually be a function of gender orientation - the stereotypic beliefs about gender that students hold- rather than of gender (see Eisenberg, Martin, \& Fabes, 1996). Gender differences in variables such as moral voice tend to disappear when gender stereotypical beliefs are accounted for (Harter, Waters, \& Whitesell, 1997). Eccles's (1987) model of educational and occupational choice posits that cultural milieu factors such as students' gender role stereotypes are partly responsible for differences in course and career selection and in confidence beliefs and perceived value of tasks and activities.

To determine the degree to which gender differences in motivation and achievement may be a function of gender stereotypic beliefs rather than of gender, Pajares and Valiante (2001) asked middle school students to report how strongly they identified with characteristics stereotypically associated with males or females in American society. A feminine orientation was associated with writing self-efficacy and rendered nonsignificant differences favoring girls in self-efficacy for self-regulation. These results foreshadow the possibility that some gender differences in academic motivation and in self-regulated learning may in part be accounted for by differences in the beliefs that students hold about their gender rather than by their gender per se.

The purpose of this study was threefold. First, we sought to provide a developmental perspective on students' confidence in their self-regulatory strategies using data obtained from cohort groups of students ranging in age from 9 to 17 (US academic levels 4 to 10). As we have explained, students' use of their self-regulatory strategies is in part dependent on the confidence they have in their academic capabilities, and researchers have reported that these academic self-efficacy beliefs tend to decrease as students progress through school. Consequently, we compare the developmental progress of students' self-efficacy for self-regulation with that of their self-efficacy beliefs in language arts. Second, we were interested in determining whether students' confidence in their self-regulatory strategies differs as a function of gender. Finally, if gender differences were detected, we sought to extend the findings that Pajares and Valiante (2001) obtained with middle school students by discovering whether these differences are a function of genderstereotypic beliefs rather than of gender both for younger and for older students. 


\section{METHOD}

\section{Participants:}

Participants were 1,257 students ranging in Grades 4 to 11 (ages 9 to 17) attending public elementary, middle, and high schools in the South or in the Northeast United States. The socioeconomic status of the schools and of the areas the schools serve were largely middle class, and students were primarily White. Only regular education students were part of the sample; gifted, special education, and English-as-a-SecondLanguage (ESL) students were not included. Instruments were group administered in individual language arts/English classes during one period at the end of the first semester of the academic year. Items were read aloud by the author to students at the elementary school levels, and students completed the instrument jointly and one item at a time. Procedures were consistent with those typically used by self-efficacy researchers.

\section{Instrument and Variables in the Study:}

Self-Efficacy for Self-Regulated Learning. The Self-efficacy for Self-regulated Learning scale is a 7item subscale adapted from Bandura's Children's Multidimensional Self-Efficacy Scales that assesses students' judgments of their capability to use various self-regulated learning strategies (see Zimmerman \& Bandura, 1994). Students were asked to respond on a 6-point Likert scale to items such as "How well can you motivate yourself to do schoolwork?" or "How well can you finish your homework on time?" A validation study by Zimmerman and Martinez-Pons (1990) revealed that a single factor underlay the items. Cronbach's alpha values ranging from .80 to .87 have been reported by researchers (Pajares et al., 1999, 2000; Pajares \& Valiante, 1999, 2001; Zimmerman \& Bandura, 1994; Zimmerman \& Martinez-Pons, 1990; Zimmerman et al., 1992). It was .81 for the present study.

Language Arts Self-Efficacy. We assessed language arts self-efficacy using Bandura's (2001) guidelines for self-efficacy assessment. Students were presented with five items asking them to provide a rating of their confidence that they could pass their language arts course with a progressively higher grade (sample items: "How confident are you that you will pass language arts at the end of this term with a grade better than a D?"; "How confident are you that you will get a grade better than a C?"). Ratings ranged from 1 (no confidence at all) to 6 (completely confident). Pajares et al. (2000) obtained an alpha coefficient of .88. We obtained 90 .

Academic Competence. Teacher ratings of students' academic competence is acknowledged as a reliable assessment of students' actual competence (Hoge \& Butcher, 1984). Consequently, the students' language arts teachers were asked to rate their students' capability in their language arts class on a 5-point scale (mirroring the A to F grading scheme typically used in the United States). This assessment was made toward the end of the first semester, after teachers had become amply familiar with their students academic work (see Pajares et al., 1999, 2000; Pajares \& Valiante, 1999, 2001, for similar procedures). In this study, we take the liberty of referring to language arts competence as academic competence both because language arts is a basic foundation of academic curricula and because, along with mathematics, it is acknowledged the primary component of academic competence.

Gender Orientation. Gender orientation beliefs were assessed by asking students to report how strongly they identify with characteristics stereotypically associated with males or females in American society (see Harter et al., 1997). Early on, researchers used gender orientation as a unidimensional construct measured using a single score such that low masculinity indicated high femininity (see Constantinople, 1973). Modern researchers agree that gender orientation is not unidimensional. Rather, they contend that masculinity and femininity are orthogonal variables that represent two distinct dimensions of individuals' self-conceptions. An individual can possess both high masculinity and high femininity (termed androgyny) or, conversely, low masculinity and low femininity (termed undifferentiated) (Ballard-Reisch \& Elton, 1992; Harter et al., 1997). For the present study, gender orientation was assessed with items used by Pajares and Valiante (2001). These items were first used in various studies by Harter and her colleagues (see Harter et al., 1997) and adapted primarily from the short form of the Children's Sex Role Inventory (CSRI) (Boldizar, 1991) (sample masculinity item: "I like building and fixing things"; sample femininity item: "I am a warm person and express these feelings to those I feel close to."). Pajares and Valiante reported that factor loadings for the 7 femininity items ranged from .55 to .80 ; loadings for the 7 masculine items ranged from .43 to .66 . The interfactor correlation was -.09 . Cronbach's alpha reliability was .76 for masculinity and .88 for femininity. In the present study, we obtained .76 for masculinity and .86 for femininity. 
Analyses:

To determine whether self-efficacy for self-regulation and language arts self-efficacy beliefs differ as a function of grade level and gender, multivariate analysis of variance (MANOVA) was conducted. This was supplemented by a trend analysis. Because group differences in self-efficacy can often be accounted for by achievement indexes (see Schunk \& Pajares, in press), we also conducted a multivariate analysis of covariance (MANCOVA) with academic competence as covariate. To determine whether gender differences in self-efficacy for self-regulation and language arts self-efficacy could be explained by gender orientation beliefs, MANCOVA was conducted with femininity and masculinity as covariates.

\section{Results}

Means (SDs) and correlations for variables in the study are provided on Table 1. Femininity correlated with self-efficacy for self-regulation (.36) and with language arts self-efficacy (.21). As the table illustrates, girls had both stronger self-efficacy for selfregulation, $t(1255)=3.75, p<.001$, and language arts self-efficacy, $t(1255)=4.16, p<.0001$, than did boys. The negative correlation between self-efficacy for self-regulation and students' age (-.30) is particularly noteworthy and foreshadows results of the subsequent MANOVA.

Multivariate analyses of variance conducted to discover gender and grade level differences in self-efficacy for self-regulation detected significant multivariate effects both for gender, Wilks' $\lambda=.98, F(2,1240)=11.47, p<.0001$, and for grade level, Wilks' $\lambda=.87, F(14,2480)=12.81, p<.0001$. Their interaction was nonsignificant. Results are illustrated on Table 2. Analyses of variance revealed that gender differences favored girls, $F(1,1241)=17.53, p<.0001$. As can be observed on Fig. 1, grade level differences revealed that students' self-efficacy for self-regulation decreased steeply from Grade 4 until Grade 7, at which point it stabilized. Note that language arts self-efficacy showed a similar, though not so steep decrease.

Trend analyses revealed a significant linear trend for language arts self-efficacy, $F(1$, $1241)=15.95, p<.0001$ and a quadratic trend for self-efficacy for self-regulation, $F(1$, 1241) $=27.71, p<.0001$. As Fig. 1 illustrates, at Grades 4 and 5 (elementary school),

Table 1. Means, Standard Deviations, and Zero-order Correlations for Variables in the Study by Gender

\begin{tabular}{lccccccccc}
\hline & \multicolumn{2}{c}{ Girls } & \multicolumn{1}{c}{ Boys } \\
& $M$ & $S D$ & 1 & 2 & 3 & 4 & 5 & $M$ & $S D$ \\
\hline 1. Self-regulation & 4.52 & 0.95 & - & $.50^{* * *}$ & $.25^{* * *}$ & $.38^{* * *}$ & $-.31^{* * *}$ & 4.31 & 1.02 \\
2. LA self-efficacy & 4.83 & 1.04 & $.51^{* * *}$ & - & $.14^{* *}$ & $.21^{* * *}$ & $-.10^{*}$ & 4.57 & 1.15 \\
3. Masculinity & 4.23 & 0.89 & $.16^{* * *}$ & $.10^{*}$ & - & $.26^{* * *}$ & $-.20^{* * *}$ & 5.02 & 0.77 \\
4. Femininity & 5.07 & 0.72 & $.30^{* * *}$ & $.15^{* *}$ & $.12^{*}$ & - & -.04 & 4.43 & 1.01 \\
5. Age & 12.89 & 2.24 & $-.30^{* * *}$ & $-.13^{* *}$ & $-.13^{* *}$ & .03 & - & 12.93 & 2.34 \\
\hline
\end{tabular}

Note: Correlations for girls are on the lower portion of the diagonal and for boys on the upper portion. Means for self-efficacy, self-regulation, masculinity, and femininity reflect the 6 points of the Likert scale. ${ }^{*} p<.05, * * p<.001,{ }^{* * *} p<.0001$ 
Table 2. Analysis of Variance of Self-Efficacy for Self-Regulation as a Function of Gender and Grade Level

\begin{tabular}{lrrrcc}
\hline \multicolumn{1}{c}{ Source } & $d f$ & \multicolumn{1}{c}{$S S$} & $M S$ & $F$ & $\omega^{2}$ \\
\hline Gender & 1 & 19.78 & 19.78 & $16.77^{* * *}$ & .01 \\
Grade Level & 7 & 30.35 & 4.34 & $3.68^{* *}$ & .01 \\
Gender*Grade Level & 7 & 8.71 & 1.24 & 1.06 & .00 \\
Error & 1241 & 1463.25 & 1.18 & & \\
Total & 1256 & 1522.73 & & & \\
\hline
\end{tabular}

Note: Model R-square $=.04 .{ }^{*} p<.05 .{ }^{*} p<<.001 . * * * p<.00001$

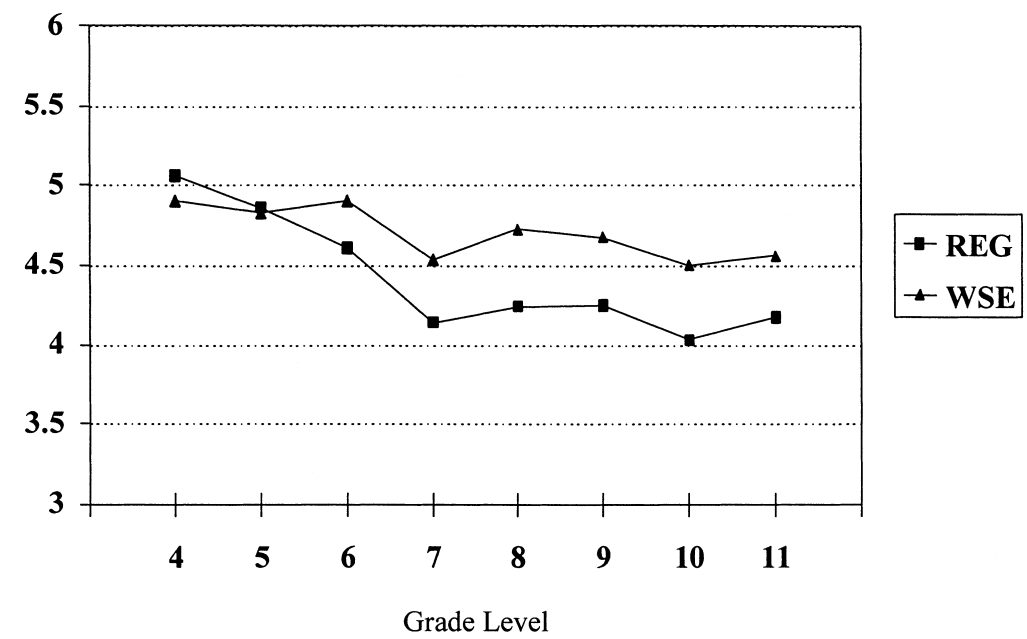

Fig. 1. Grade level differences in self-efficacy for Self-Regulation (REG) and Writing Self-Efficacy (WSE).

students' self-regulatory and language arts confidence did not differ. Language arts selfefficacy began to decrease at Grade 7. Self-efficacy for self-regulation showed a steeper decrease beginning earlier, with a slight recovery at Grade 11. The quadratic slope of selfefficacy for self-regulation $(\beta=-.868)$ differed markedly from the linear slope for language arts self-efficacy $(\beta=-.109)$.

Group differences in self-efficacy sometimes disappear when academic achievement is controlled. Because we wanted to discover whether gender and grade level differences in self-efficacy for self-regulation were a function of academic competence, we reanalyzed the ANOVA model adding teacher ratings of students' academic competence as a covariate and including all two-way interactions. Gender and grade level differences were each maintained, $F(7,1232)=4.41, p<.05$ gender; $F(7,1232)=6.29, p<.0001$ grade level.

The MANCOVA conducted to discover whether gender differences were a function of gender orientation again included grade level, as well as masculinity and femininity as 
Table 3. Analysis of Covariance of Self-Efficacy for Self-Regulation as a Function of Gender and Grade Level, with Masculinity and Femininity as Covariates

\begin{tabular}{lrrrrr}
\hline \multicolumn{1}{c}{ Source } & $d f$ & \multicolumn{1}{c}{$S S$} & \multicolumn{1}{c}{$M S$} & \multicolumn{1}{c}{$F$} & $\omega^{2}$ \\
\hline Gender & 1 & 1.63 & 1.63 & 2.14 & .00 \\
Grade Level & 7 & 115.57 & 16.51 & $21.64^{* * *}$ & .09 \\
Masculinity & 1 & 8.82 & 8.82 & $11.56^{* *}$ & .01 \\
Femininity & 1 & 106.63 & 106.63 & $139.76^{* * *}$ & .09 \\
Error & 1246 & 950.68 & 0.76 & & \\
Total & 1256 & 1247.93 & & & \\
\hline
\end{tabular}

Note: Model R-square $=.24 .{ }^{*} p<.05 .{ }^{* *} p<.001 .{ }^{* * *} p<.00001$

covariates. There were no significant interactions between gender and either masculinity or femininity. MANCOVA with nonsignificant interactive effects removed revealed multivariate effects for masculinity, Wilks' $\lambda=.99, F(2,1245)=6.22, p<.005$, femininity, $\lambda=.90, F(2,1245)=70.16, p<.0001$, gender, $\lambda=.99, F(2,1245)=3.47, p<.05$, and grade level, $\lambda=.88, F(14,2490)=11.48, p<.0001$.

ANCOVA results followed by tests of the difference between the adjusted means revealed that gender differences previously found in self-efficacy for self-regulation were rendered nonsignificant when controls for femininity and masculinity were included in the model. A feminine orientation had a significant effect on self-efficacy for self-regulation $\left(\omega^{2}=.09\right), F(1,1246)=139.76, p<.0001$, and there was a modest influence of masculinity $\left(\omega^{2}=.01\right), F(1,1246)=11.56, p<.001$. As expected, gender orientation beliefs had no influence on grade level differences. Results of this ANCOVA are provided on Table 3.

To extend the findings of Pajares and Valiante (2001), we analyzed data separately for elementary school and high school students. In each case, gender differences were rendered nonsignificant when masculinity and femininity were included as covariates. As was the case with the total sample, both femininity $\left(\omega^{2}=.08\right), F(1,303)=15.90, p<.0001$, and masculinity $\left(\omega^{2}=.03\right), F(1,303)=6.17, p<.05$, proved significant for elementary school students. At the high school level, the influence of femininity was again pronounced $\left(\omega^{2}=.08\right), F(1,464)=37.47, p<.0001$, and the influence of masculinity modest $\left(\omega^{2}=.01\right)$, $F(1,464)=4.13, p<.05$.

\section{DISCUSSION}

The purpose of this study was to provide a developmental perspective on students' confidence in their self-regulatory strategies using data obtained from cohort groups of students ranging from age 9 to 17 , to determine whether this confidence differs as a function of gender, and to discover whether these differences are a function of gender orientation beliefs rather than of gender. As regards the developmental progression of 
students' self-efficacy beliefs, we found that students' confidence in their self-regulatory learning strategies decreased as students progressed from elementary school to high school. Even more troubling, this decrease was even steeper than a similar decrease in students' self-perceptions of their academic competence.

Students' self-efficacy beliefs strongly influence their academic motivation, the selfregulated learning strategies they use in school, and the academic success they ultimately attain. The finding of diminishing confidence in the use of self-regulatory practices is troublesome because, when students lose confidence in their academic strategies and practices, they are less likely to employ them (Bandura, 1997). It seems clear that educational programs that seek to empower students must make students' beliefs about their self-regulatory practices a focus of professional practice. Teachers face a dual responsibility in this regard. They must help students develop sound self-regulatory practices while at the same time buttressing the confidence that students will require to employ those practices frequently and effectively.

Other researchers have reported that students' motivation can diminish during the middle school years (see Eccles, Wigfield, Flanagan, Miller, Reuman, \& Yee, 1989; Harter, Whitesell, \& Kowalski, 1992). This decline in self-beliefs during early adolescence may in part be a function of the transition to middle/junior high school. This transition often introduces a larger social comparison group; a greater emphasis on grades and competition; and a larger, less personal environment. Moreover, these environmental changes arrive at a time when young people are undergoing critical developmental changes that may themselves be responsible for the diminishing motivation (or for a shift in their response set to attitude instruments). Changes in perceived ability are not uniform across subject domains. Eccles et al. (1989) reported that self-perception of ability in mathematics showed a decline over the course of Grade 7, after the transition to middle school, whereas self-perception of ability in English steadily declined over the course of both Grade 6 and Grade 7. Clearly, self-efficacy beliefs can have a long-term effect on the lives of middle school students, for beliefs about academic capabilities can influence future course-taking patterns that may in turn enable or foreclose future career options.

Gender differences in self-efficacy for self-regulation favored girls, but these differences were rendered nonsignificant when gender orientation beliefs were controlled. Instead, a feminine orientation was particularly adaptive. These findings support the contentions of researchers who have found that gender differences in the academic motivation of middle school students may be a function of the stereotypical beliefs that students hold about gender (Pajares \& Valiante, 2001), and they extend these findings to elementary and high school students.

Social cognitive theory does not endow gender self-beliefs with motivating properties (Bussey \& Bandura, 1999), but neither does it endow gender with such properties. Researchers have long observed that fields such as mathematics, science, and technology are typically viewed by students as being within a male-domain (Eisenberg et al., 1996). In these areas, a masculine orientation is associated with confidence and achievement because masculine self-perceptions are themselves imbued with the notion that success in these areas is a masculine imperative. 
The use of academic self-regulatory practices may well be associated with a feminine orientation in part because the types of practices typically measured are viewed as those that the more committed students possess (e.g., finishing homework on time, studying when there are other interesting things to do, concentrating on school work, arranging a place to study at home where one will not get distracted). They are indeed just the very sorts of behaviors that the stereotypically studious student (a girl) is likely to manifest but the stereotypically rambunctious student (a boy) is likely to eschew. As a consequence, a feminine orientation, either on its own or accompanied by a masculine orientation, is associated with the beliefs related to self-regulatory success. One challenge before parents and teachers is to alter students' views of self-regulation so that it is perceived as relevant and valuable both to boys and to girls. A challenge for all educators, and for the broader culture, is to continue to expound and model gender self-beliefs that encompass both the feminine expressiveness and the masculine instrumentality that are critical to a balanced self-view.

\section{REFERENCES}

Ballard-Reisch, D., \& Elton, M. 1992. Gender orientation and the Bem sex-role inventory: A psychological construct revisited. Sex Roles, 27, 291-306.

Bandura. A. 1977. Self-efficacy: Toward a unifying theory of behavioral change. Psychological Review, 84, 191-215.

Bandura, A. 1986. Social foundations of thought and action: A social cognitive theory. Englewood Cliffs, NJ: Prentice Hall.

Bandura, A. 1997. Self-efficacy: The exercise of control. New York: Freeman.

Bandura, A. 2001. Guide for constructing self-efficacy scales. Available from Albert Bandura, Stanford University.

Boldizar, J. 1991. Assessing sex typing and androgyny in children: The children's sex role inventory. Developmental Psychology, 27, 505-515.

Bouffard-Bouchard, T., Parent, S., \& Larivèe, S. 1991. Influence of self-efficacy on self-regulation and performance among junior and senior high-school aged students. International Journal of Behavioral Development, 14, 153-164.

Bussey, K., \& Bandura, A. 1999. Social cognitive theory of gender development and differentiation. Psychology Review, 106, 676-713.

Constantinople, A. 1973. Masculinity-Femininity: An exception to a famous dictum? Psychological Bulletin, 80, 389-407.

Eccles, J. S. 1987. Gender roles and women's achievement-related decisions. Psychology of Women Quarterly, 11, 135-172.

Eccles, J. S., Wigfield, A., Flanagan, C. A., Miller, C., Reuman, D. A., \& Yee, D. 1989. Self-concepts, domain values, and self-esteem: Relations and changes at early adolescence. Journal of Personality, 57, 283-310.

Eisenberg, N, Martin, C. L., \& Fabes, R. A. 1996. Gender development and gender effects. In D. C. Berliner \& R. C. Calfee (Eds.), Handbook of educational psychology (pp. 358-396). New York: Simon \& Schuster Macmillan.

Hackett, G. 1995. Self-efficacy in career choice and development. In A. Bandura (Ed.), Self-efficacy in changing societies (pp. 232-258). New York: Cambridge University Press.

Harter, S., Waters, P., \& Whitesell, N. 1997. Lack of voice as a manifestation of false self-behavior among adolescents: The school setting as a stage upon which the drama of authenticity is enacted. Educational Psychologist, 32, 153-173.

Harter, S., Whitesell, N. R., \& Kowalski, P. 1992. Individual differences in the effects of educational transitions on young adolescent's perceptions of competence and motivational orientation. American 
Educational Research Journal, 29, 777-807.

Hoge, R. D., \& Butcher, R. 1984. Analysis of teacher judgments of pupil achievement levels. Journal of Educational Psychology, 76, 777-781.

Pajares, F. 1997. Current directions in self-efficacy research. In M. Maehr \& P. R. Pintrich (Eds.), Advances in motivation and achievement (Vol. 10, pp. 1-49). Greenwich, CT: JAI Press.

Pajares, F. 2001. Toward a positive psychology of motivation. Journal of Educational Research, 95, 27-36.

Pajares, F. in press. Self-efficacy beliefs, motivation, and achievement in writing: A review of the literature. Reading and Writing Quarterly.

Pajares, F., Britner, S., \& Valiante, G. 2000. Writing and science achievement goals of middle school students. Contemporary Educational Psychology, 25, 406-422.

Pajares, F., Miller, M. D., \& Johnson, M. J. 1999. Gender differences in writing self-beliefs of elementary school students. Journal of Educational Psychology, 91, 50-61.

Pajares, F., \& Valiante, G. 1999. Grade level and gender differences in the writing self-beliefs of middle school students. Contemporary Educational Psychology, 24, 390-405.

Pajares, F., \& Valiante, G. 2001. Gender differences in writing motivation and achievement of middle school students: A function of gender orientation? Contemporary Educational Psychology, 26, 366-381.

Pintrich, P. R., \& De Groot, E. V. 1990. Motivational and self-regulated learning components of classroom academic performance. Journal of Educational Psychology, 82, 33-40.

Pokay, P., \& Blumenfeld, P. C. 1990. Predicting achievement early and late in the semester: The role of motivation and use of learning strategies. Journal of Educational Psychology, 82, 41-50.

Schunk, D. H., \& Ertmer, P. A. 2000. Self-efficacy and academic learning: Self-efficacy enhancing interventions. In M. Boekaerts, P. R. Pintrich, \& M. Zeidner (Eds.), Handbook of self-regulation (pp. 631-650). San Diego, CA: Academic Press.

Schunk, D. H., \& Pajares, F. in press. The development of academic self-efficacy. In A. Wigfield \& J. Eccles (Eds.), Development of achievement motivation. San Diego, CA: Academic Press.

Stipek, D. 1998. Motivation to learn: From theory to practice (3rd ed.). Boston: Allyn and Bacon.

Wigfield, A., Eccles, J. S., \& Pintrich, P. R. 1996. Development between the ages of 11 and 25. In D. C. Berliner \& R. C. Calfee (Eds.), Handbook of educational psychology (pp. 148-185). New York: Simon \& Schuster Macmillan.

Wigfield, A., Eccles, J., MacIver, D., Reuman, D., \& Midgley, C. 1991. Transitions at early adolescence: Changes in children's domain-specific self-perceptions and general self-esteem across the transition to junior high school. Developmental Psychology, 27, 552-565.

Winne, T. H., \& Perry, N. E. 2000. Measuring self-regulated learning. In M. Boekaerts, P. R. Pintrich, \& M. Zeidner (Eds.), Handbook of self-regulation (pp. 531-566). San Diego, CA: Academic Press.

Zimmerman, B. J. 1989. A social cognitive view of self-regulated academic learning. Journal of Educational Psychology, 81, 329-339.

Zimmerman, B. J. 1990. Self-regulating academic learning and achievement: The emergence of a social cognitive perspective. Educational Psychology Review, 2, 173-201.

Zimmerman, B. J. 1994. Dimensions of academic self-regulation: A conceptual framework for education. In D. H. Schunk \& B. J. Zimmerman (Eds.), Self-regulation of learning and performance: Issues and educational implications (pp. 3-21). Hillsdale, NJ: Erlbaum.

Zimmerman, B. J. 2000. Attaining self-regulation: A social cognitive perspective. In M. Boekaerts, P. R. Pintrich, \& M. Zeidner (Eds.), Handbook of self-regulation (pp. 13-41). San Diego, CA: Academic Press.

Zimmerman, B. J. in press. Achieving self-regulation: The trial and triumph of adolescence. In F. Pajares \& T. C. Urdan (Eds.), Adolescence and education, Vol. 2. Greenwich, CT: Information Age Publishers.

Zimmerman, B. J., \& Bandura, A. 1994. Impact of self-regulatory influences on writing course attainment. American Educational Research Journal, 31, 845-862.

Zimmerman, B. J., Bandura, A., \& Martinez-Pons, M. 1992. Self-motivation for academic attainments: The role of self-efficacy beliefs and personal goal setting. American Educational Research Journal, 29, 663-676.

Zimmerman, B. J., \& Martinez-Pons, M. 1990. Student differences in self-regulated learning: Relating grade, sex, and giftedness to self-efficacy and strategy use. Journal of Educational Psychology, 82, 51-59. 